\title{
FMT-PET for the Early Diagnosis of Parkinson's Disease
}

\author{
Sayaka Ono ${ }^{1,2^{*}}$, Yuko Nara ${ }^{1}$, Toshihiko Sato ${ }^{3}$ and Shin-ichi Muramatsu ${ }^{1^{*}}$ \\ ${ }^{1}$ Division of Neurology, Jichi Medical University, Tochigi, Japan \\ ${ }^{2}$ Division of Neurology, Saitama Medical Center, Jichi Medical University, Saitama, Japan \\ ${ }^{3}$ Utsunomiya Central Clinic, Tochigi, Japan
}

*Corresponding authors: Sayaka Ono, Division of Neurology, Department of Medicine, Jichi Medical University, 3311-1 Yakushiji, Shimotsuke, Tochigi 329-0498, Japan, Tel: +81-285-58-7352; Fax: +81-285-44-5118; E-mail: sasari@jichi.ac.jp

Shin-ichi Muramatsu, Division of Neurology, Department of Medicine, Jichi Medical University, 3311-1 Yakushiji, Shimotsuke, Tochigi 329-0498, Japan, Tel: +81-285-58-7352; Fax: +81-285-44-5118; E-mail: muramats@jichi.ac.jp

Rec date: Oct 30, 2014, Acc date: Oct 31, 2014, Pub date: Nov 02, 2014

Copyright: @ 2014 Ono S, et al. This is an open-access article distributed under the terms of the Creative Commons Attribution License, which permits unrestricted use, distribution, and reproduction in any medium, provided the original author and source are credited.

\section{Description}

A 56-year-old woman complained of a three-month history of progressive clumsiness in her left hand. She reported fine hand movements to have become slow and uncoordinated, thus leading to moderate difficulty in dressing and working as a beautician. A neurological examination revealed rigidity in her left limb. No obvious tremors were noted. She was treated with $\mathrm{L}$-dopa $(300 \mathrm{mg} / \mathrm{day})$, which provided substantial symptomatic benefits. MRI showed the putamen to have a normal morphology and size, and no areas of any altered signals were observed in the brain parenchyma (Figure 1A). Positron emission tomography (PET) with an aromatic L-amino acid decarboxylase (AADC) tracer, 6- $\left[{ }^{18} \mathrm{~F}\right]$ fluoro-L- $m$-tyrosine (FMT) showed a reduced uptake in the posterior part of the right putamen (Figure 1B).

In Parkinson's disease (PD), the activity of AADC in the striatum is reduced to $5 \%-20 \%$ of normal levels before cardinal motor symptoms become apparent [1]. High-resolution FMT-PET images can clearly demonstrate a reduction of the subregional AADC activities, and the lowest FMT uptake values tend to be observed in the posterior part of the putamen contralateral to the more affected limbs, even in the early stage of the disease [2]. This case therefore demonstrated the diagnostic value of using FMT-PET in the diagnosis of mild PD, particularly when encountering patients that do not show any remarkable tremors while at rest.

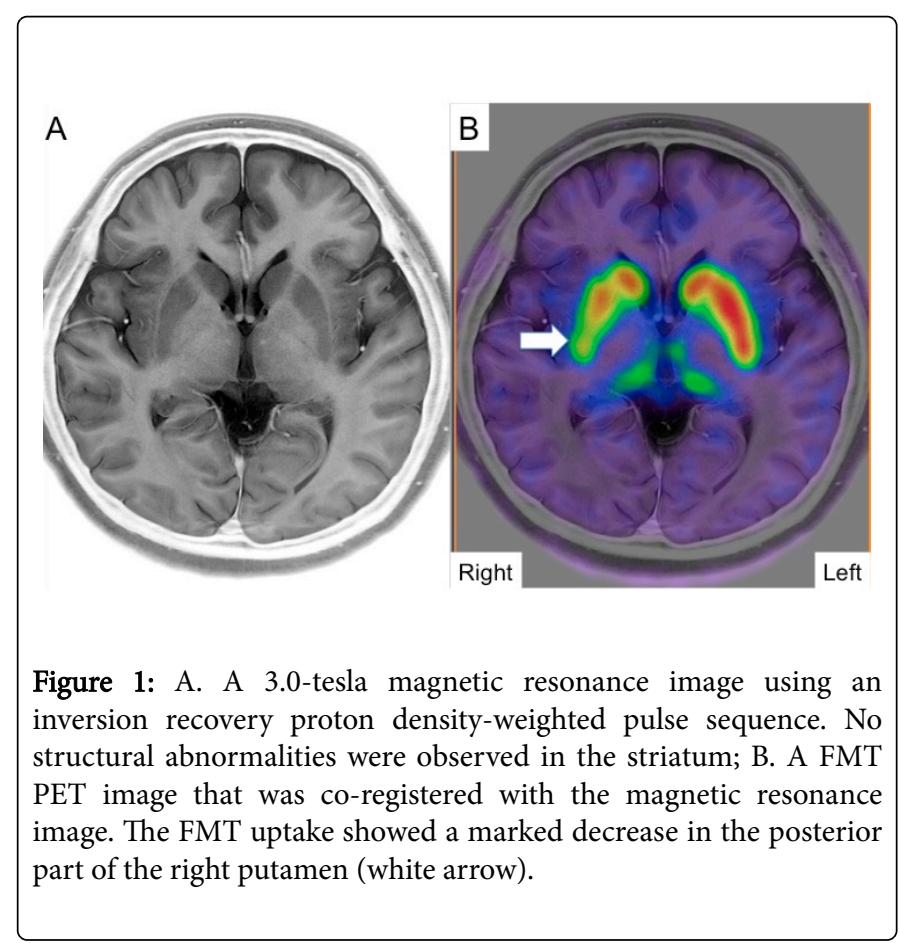

\section{References}

1. Nagatsu T, Ichinose H (1999) Molecular biology of catecholamine-related enzymes in relation to Parkinson's disease. Cell Mol Neurobiol 19: 57-66.

2. Asari S, Fujimoto K, Miyauchi A, Sato T, Nakano I, et al. (2011) Subregional $6-\left[{ }^{18} \mathrm{~F}\right]$ fluoro-L- $m$-tyrosine uptake in the striatum in Parkinson's disease. BMC Neurol 11: 35. 